\title{
Effect of reinforcement material on impact properties of epoxy
}

\author{
Basim M. Fadhil \\ Manufacturing Engineering Dept. \\ Koya university \\ Koya,Iraq \\ basim.fadhil@koyauniversity.org
}

\author{
Payman Sahbah Ahmed \\ Manufacturing Engineering Dept. \\ Koya university \\ Koya,Iraq \\ payman.suhbat@koyauniversity.org
}

\author{
Ava Ali Kamal \\ Mechanical and Energy Engineering Dept. \\ Erbil Polytechnic University \\ Erbil, Iraq \\ avaalikamall@gmail.com
}

\begin{abstract}
Impact characteristics of Epoxy matrix composites is investigated by impact machine. Four different types of reinforcement are used in the experimental works: type one: $1.9 w \%$ steel fiber, $1.9 w t \%$ carbon fiber,1.9 wt\% carbon nanotube, 1.9 wt\% woven carbon fiber.

This work shows that reinforcing epoxy with (1.9 wt\% of woven carbon fiber) improves the impact properties where energy, force and deformation values of impact test for this composite were $18.4 \mathrm{~J}, 3580.59 \mathrm{~N}$ and $18 \mathrm{~mm}$ respectively while for epoxy were $2.927 \mathrm{~J}, 921.849 \mathrm{~N}$ and 18.413 mm respectively.
\end{abstract}

Keywords: epoxy, nanotube, carbon fiber, steel fiber

\section{INTRODUCTION}

There is a huge range of engineering applications of fiber-reinforced laminated composite materials such as: transport, aerospace, fabrication according light weight, strength and high specific stiffness. Nevertheless, those composites are critical to impact damage and deterioration, especially in case of out-of-plane impact, that might be make deterioration incident at and low impact kinetic energies [1-2].

Many researches investigates impact by drop weight of fiber-reinforced composites. Basim M. F. et. al. has used $(0,0.2,0.4,0.6,0.8$, and 1) wt.\% multi-walled carbon nanotubes (MWCNTs) as reinforcement in epoxy resin. Tensile and drop weight impact test are used to evaluate the mechanical properties of the composites. Results shows that adding 0.2 wt.\% of MWCNTs enhance and increase the tensile properties and Adding $0.6 \mathrm{wt} . \%$ of MWCNTs enhance the impact properties [3].

Impact characteristics of epoxy matrix composites have been studied by Payman S. A. et. al. [4], a drop weight impact machine with spherical steel nose with different values of kinetic energies has been used. Woven glass + carbon, woven glass, unidirectional carbon were uesd. This study concludes that the impact properties of epoxy improved with glass, unidirectional and woven carbon. Arturas et. Al. investigated the impact response of woven carbon/epoxy and E-Glass / epoxy composite systems on vehicle body structures [1]. It has been found that elastic of E-glass / epoxy composite materials was more than 1.5 times of that carbon epoxy composite which describes the formation of smaller areas of deterioration.

G. Agarwal et. al investigate the effect of fiber percentages of bidirectional and short carbon fiber reinforced epoxy on physical, mechanical and thermomechanical properties respectively. The five different fiber percent sages, i.e., 10wt. \%, 20wt. \%, 30wt. \%, $40 \mathrm{wt} . \%$ and $50 \mathrm{wt}$. $\%$ were taken for evaluating the above mentioned properties. The impact strength is determined to represent the behavior of composite structures with that of fiber percentages. The results show that with the increase in fiber percentages the mechanical properties of bidirectional carbon fiber reinforced epoxy composites increase as compared to short carbon fiber reinforced epoxy composites [5].

Hossein Rahmaniet al. [6] investigates the influence of resin types, number of laminates, and fiber directions, on mechanical properties of laminated composites. To study the fiber orientation effect, angles of $0^{\circ}, 35^{\circ}, 45^{\circ}$, and $90^{\circ}$ have been selected. It has been found that the impact strengths were entirely dependent on the fiber directions and by the number of laminates. The results indicated that the mechanical properties of composites made with five ply were generally slightly greater than three-ply composites. It may be due to the bond line defects, which adversely influence the mechanical properties. Scanning micrographs of the composites showed that the epoxy matrix material was fully adhered to the fibers, indicating a strong interface. It can be concluded that the order of increasing limits in the mechanical properties of the composites is fiber orientation greater than number of laminates greater than resin type.

Raghad Hussein Mohammed [7] investigated the impact characteristics of some epoxy composites materials. Those composites were reinforced with chopped carbon fibers, glass fibers (woven) and hybrid carbon fibers (chopped) with volume fraction (30) \% for each type. It has been found that the hybrid composite $(\mathrm{C}+\mathrm{G} /$ Epoxy) have the higher mechanical properties than others. The impact strength for (C/epoxy) composites are lower than the strength of $(\mathrm{C}+\mathrm{G} / \mathrm{epoxy})$ composite due to the brittle characteristics of carbon fibers.

Sunith Babu L and H. K. Shivan [8] investigated the impact property of carbon fiber and E-glass/epoxy composite, this study conducted with impact of steel impactor at low kinetic energy. All experiments were performed by using a drop weight impact tester and presented for cross-ply laminates [0 - 90] combination. All experimental tests showed that an increased deflection for glass composites, that lead to a higher extent of coposite damage compared to the carbon fiber one, laminates composite plates with delamination as one important energy absorption mechanism. From the 
above result carbon fiber reinforced composites has more strength than glass fiber reinforced composites.

Payman S. A. [9] studied the effect of impactor design on the impact properties of epoxy composites reinforced with unidirectional glass, unidirectional carbon, woven glass and hybrid woven (glass + carbon) fibers. This research shows that changing the impactor design have no effect on impact properties of woven reinforced composites while it has a significant effect on unidirectional fiber reinforced composites, and glass fiber reinforced composites have a better impact property than carbon reinforced composites.

A drop weight impact tester was used in this work to study the impact characteristics of composites (epoxy matrix) by spherical steel impactor. Four kinds of reinforcement have been used in the this study: steel fiber, carbon fiber, carbon nanotube and woven carbon fiber.

\section{EXPERIMENTAL WORK}

In this study hand lay -up molding method is used in preparing specimens of composites. The specimens were made using rubber mold Fig. 1. The specimens was prepared with reinforcement weight fraction of $(1.9 \%$ wt) for samples(table 1). The epoxy ratio to hardener is (73\% to $27 \%$ ), $4 \mathrm{gm}$ from epoxy resin was mixed with $1.47 \mathrm{gm}$ of hardener. Three weeks the molds were left for to be cured at room temperature.

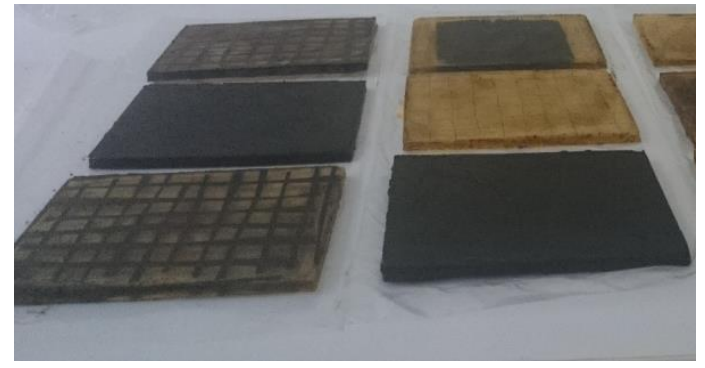

Figure 1Samples and molds

Table 1: samples description

\begin{tabular}{|c|c|c|c|c|c|c|}
\hline No. & Matrix & $\begin{array}{c}\text { specimen } \\
\text { Symbol }\end{array}$ & $\begin{array}{c}\text { fraction of } \\
\text { Matrix } \\
\text { Weight } \\
\mathrm{wt}_{\mathrm{m}} \%\end{array}$ & $\begin{array}{c}\text { Specimen } \\
\text { Dimension } \\
\mathrm{mm}\end{array}$ & Reinforcement & $\begin{array}{c}\text { Weight fraction } \\
\text { of } \\
\text { reinforcement } \\
\mathrm{Wt}_{\mathrm{f}} \%\end{array}$ \\
\hline 1 & \multirow{5}{*}{ Epoxy } & Epoxy & 100 & $100 \times 150$ & None & 0 \\
\hline 2 & & $1.9 \mathrm{cf}$ & 98.1 & $100 \times 150$ & 1.9 carbon fiber & 1.9 \\
\hline 3 & & $1.9 \mathrm{nc}$ & 98.1 & $100 \times 150$ & 1.9 nanocarbon & 1.9 \\
\hline 4 & & $1.9 \mathrm{wc}$ & 98.1 & $100 \times 150$ & 1.9 woven carbon fiber & 1.9 \\
\hline 5 & & $1.9 \mathrm{sf}$ & 98.1 & $100 \times 150$ & 1.9 steel fiber & 1.9 \\
\hline
\end{tabular}

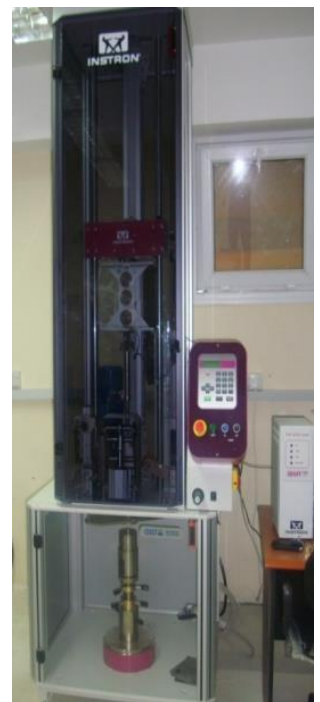

Figure 2 Impact tester machine

To characterization the damage mechanism, all experiments were conducted when composite deformed with low velocity impact. all tests have been carried out at room temperature on the four composite materials using a drop weight (steel hemispherical impactor diameter $=20 \mathrm{~mm}-$ impactor weight $=2.8 \mathrm{~kg}$ ), with impact velocity of $3.58 \mathrm{~m} / \mathrm{sec}$. An Instron 9350 impact tester has been used in this work (see Figure 2). The dimensions of the composites are is $100 \mathrm{~mm}$ by $150 \mathrm{~mm}$. all recorded data are: energy, velocity, displacement, impactor force history.

\section{RESULTS AND DISCUSSION}

The relationships of force-time, energy-time, forcedeformation, and energy-deformation were obtained as follows:

- Force - Time and Force - Deformation behaviors

The impact force-time curves show the duration of the contact between impactor and specimen surface, the maximum force reached and the appearance of damage (See Fig. 3). The force-deformation curves give the specimen's stiffness (slope of the curve), the maximum deformation and some information about damage onset (see Fig. 4).

The first type of damage is matrix cracking, which does not significantly change the overall stiffness of laminates. However, matrix cracks tips may act as onset sites for delamination and fiber breakage which do change the local stiffness of laminates [10]. In addition, the specimen can absorb the impact energy by other means including indentation (representative of local matrix crushing and local fiber breakage), delamination, splitting or fibers peeling on the non-impacted side [11]. For all composites the onset of the first damage can be 


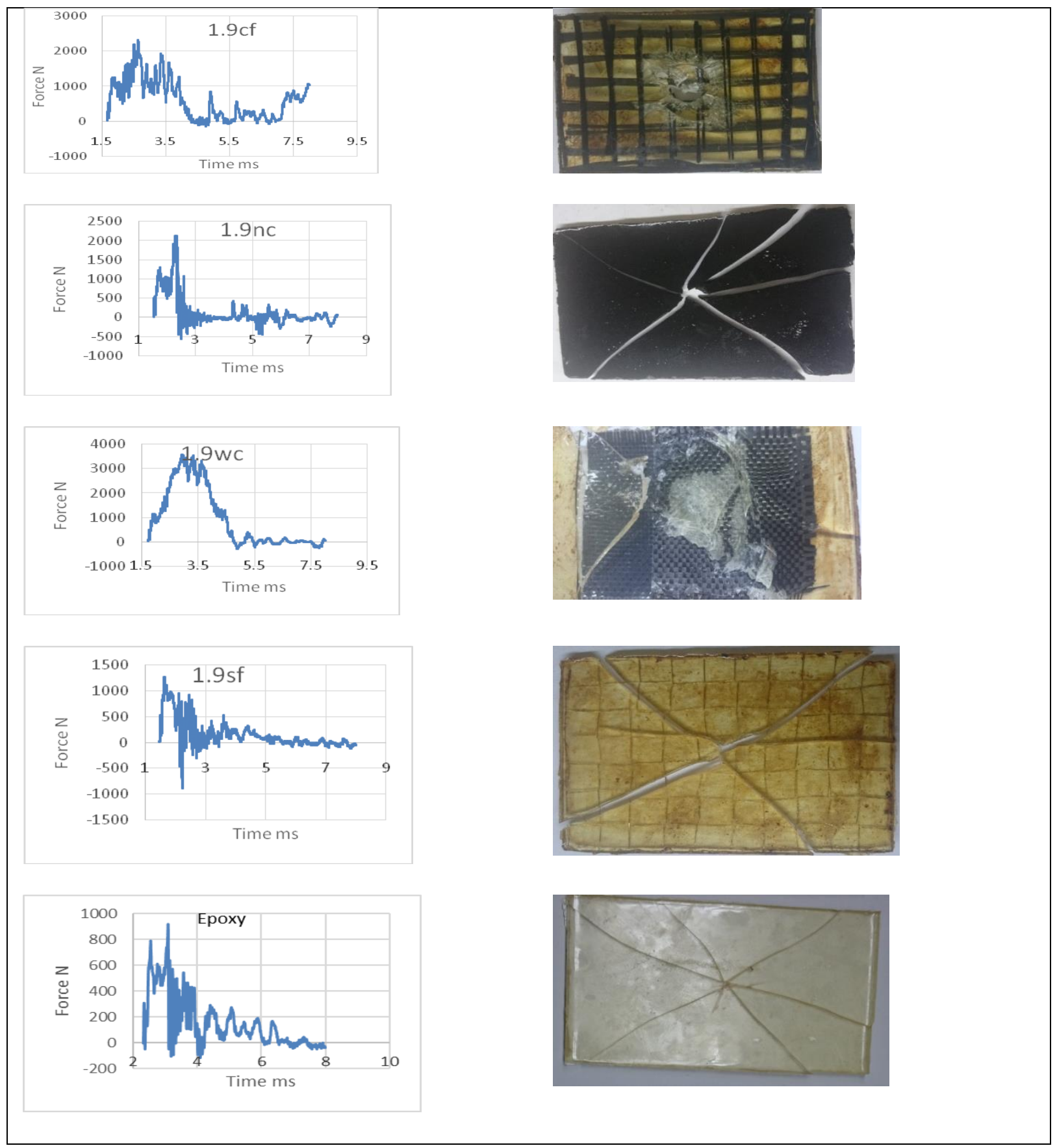

Figure 3 Force - time relationship and damaged samples of the composites

There is an oscillating change in the force with time in all samples. For $(1.9 \mathrm{cf})$ composites there is an oscillating increase until the maximum force reached followed by an oscillating decrease at around $4 \mathrm{~ms}$ and the force value keep low until the end of the test reaching to the maximum deformation of $20.5 \mathrm{~mm}$. This increase in the force is due to carbon fiber which make crack growth suppressed due to the arrangement of fibers in bidirectional way.

For (1.9nc) composites there is a sharp increase in the force at around $2 \mathrm{~ms}$ followed by a sharp decrease at around $2.5 \mathrm{~ms}$, the force keeps in decreasing in an oscillating manner until the end of the test where the crack reaches to critical value which make it grow spontaneously through the composite, reaching to the maximum deformation of $22.6 \mathrm{~mm}$.

For $(1.9 \mathrm{wc})$ composites there is a sharp increase in the force at around $2 \mathrm{~ms}$ and the form of failure is limited to the matrix and the woven fibers are not affected at all due to high strength of the carbon in addition to the woven arrangement of the fiber which resist the crack and failure, then there is a sharp decrease at around 5 msreaching to the maximum deformation of $18 \mathrm{~mm}$. For $(1.9 \mathrm{sf})$ composites there is a sharp increase in the force at around $2 \mathrm{~ms}$ and decrease in the force around $2.5 \mathrm{~ms}$, the force keeps in decreasing in an oscillating 
manner until the end of the test where the crack reaches to critical value which make it grow spontaneously through the composite, reaching to the maximum deformation of $22.8 \mathrm{~mm}$. This increase in the force is due to steel fiber which make crack growth suppressed due to the arrangement of fibers in bidirectional way.

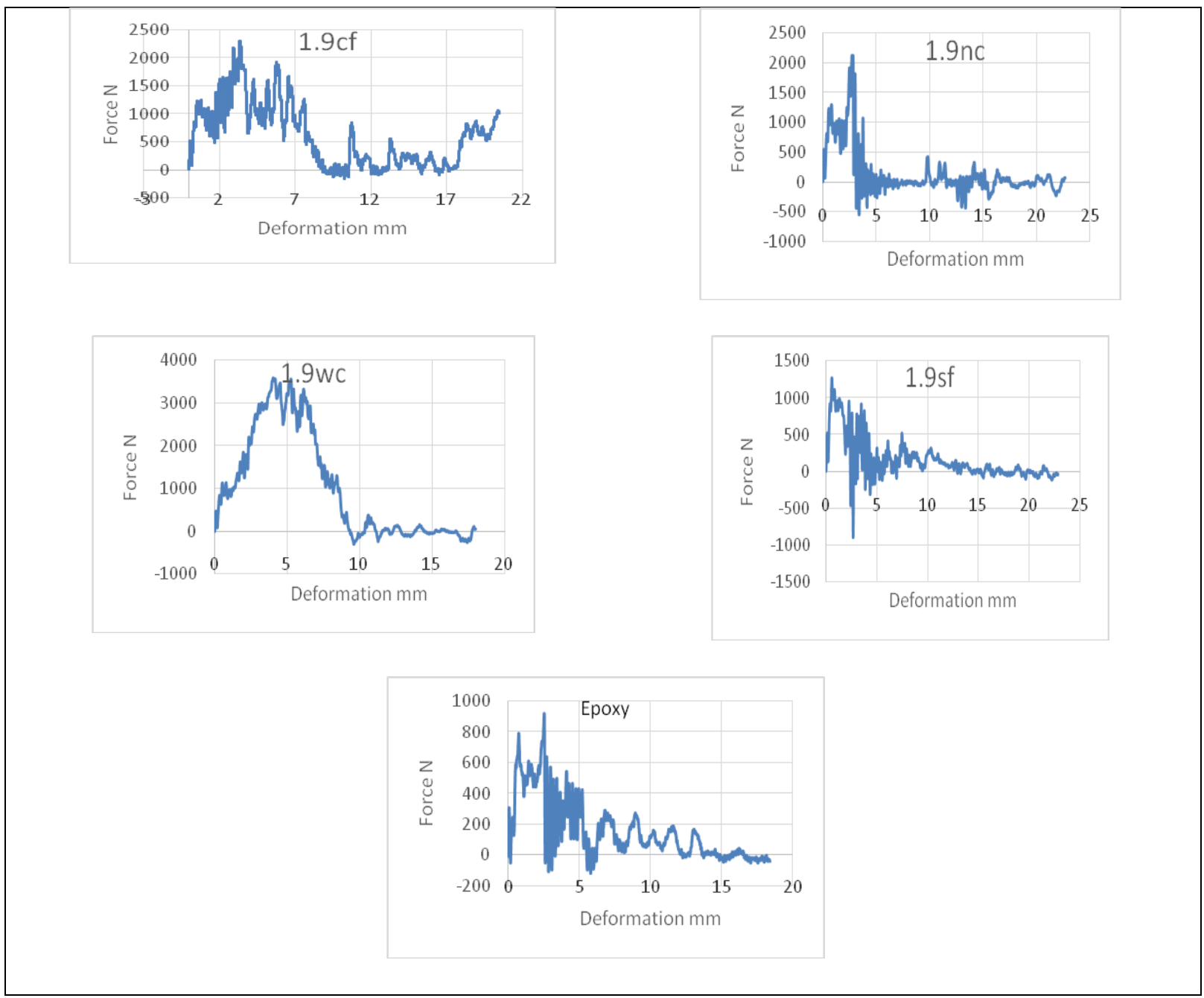

Figure 4 Force- Deformation relationship of the composites

For epoxy the force reaches its maximum value at around $2.5 \mathrm{~ms}$. After $2.5 \mathrm{~ms}$ the force keeps in decreasing in an oscillating manner until the end of the test. Maximum force value can be found in $(1.9 \mathrm{wf})$ with $3580.597 \mathrm{~N}$ because of the combined effect of high strength and the woven arrangement of carbon fiber, followed by cf, nc, sf, and epoxy. Maximum deformation value can be found in 1.9 sf with $22.84 \%$ $\mathrm{mm}$ because of the metallic behavior of steel fiber which lead to more deformation before fracture, followed by nc, cf, epoxy, and wc give the minimum value of deformation of $18 \%$.

- Impact Energy - Time and Energy - Deformation behaviors

The impact energy-time curves show the duration of the contact between impactor and specimen surface, the maximum energy reached, where it can be seen that energy keep in increasing until it reaches its maximum value for all composites (See Fig. 5). The energy- deformation curves give the specimen's toughness and the maximum deformation (see Fig. 6). For 1.9cf the impact energy is high due to the high strength and the bidirectional arrangement of fibers which resist crack growth, while the presence nanocarbon reinforcement showed low impact energy absorption and failure compared with others due to sensitivity to impact damage because of the brittle properties besides conglomerate which are considered as a shortcoming in the composite construction. For $1.9 \mathrm{wc}$ composites there is a high increase in the energy due to high strength of the carbon in addition to the woven arrangement of the fiber which resist the crack and failure. Due to metallic fibers which possesses of plastic deformation characteristic, make fibers as a crack obstructer, in the case of 1.9sf composites.Maximum energy value can be found in $1.9 \mathrm{wc}$ with $18.4 \mathrm{~J}$, followed by $\mathrm{cf}, \mathrm{sf}$, nc, and epoxy give the minimum value of deformation of $2.927 \mathrm{~J}$. 


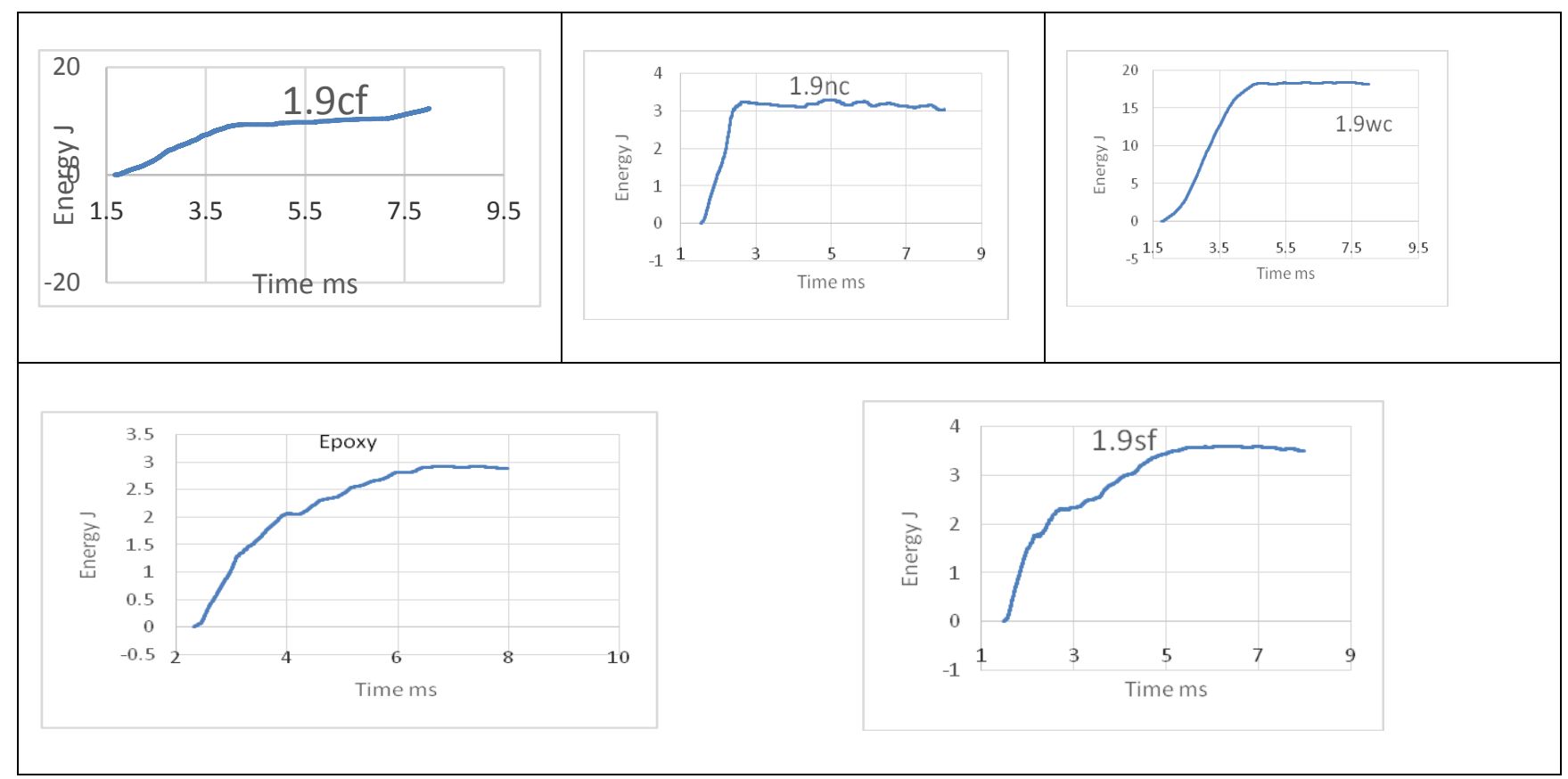

Figure 5 Energy - time relationship of the composites

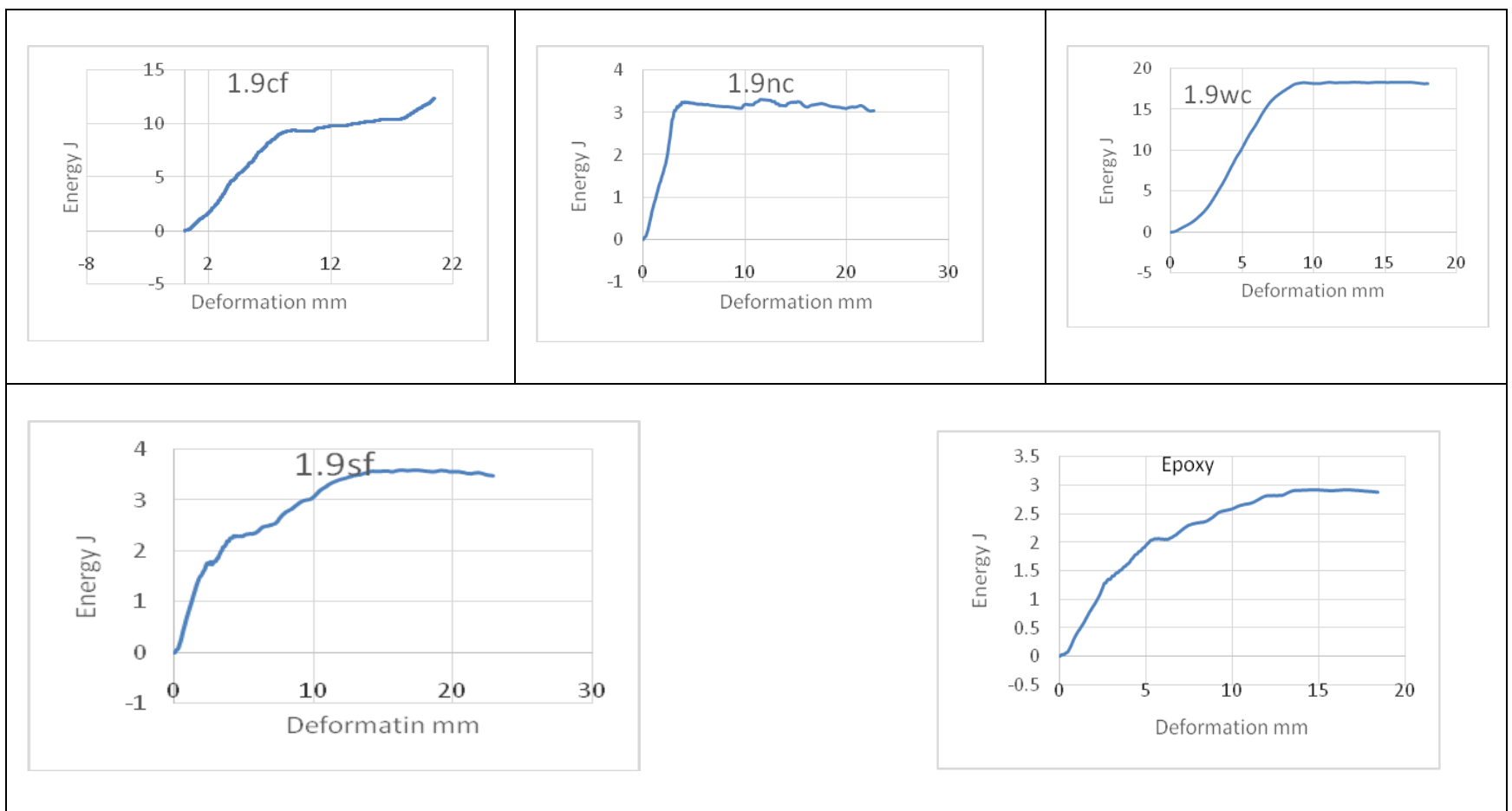

Figure 6 Energy - deformation relationship of the composites

\section{CONCLUSION}

This work showed that: For 1.9cf the impact properties is high due to the high strength and the bidirectional arrangement of fibers which resist crack growth, while the presence nanocarbon reinforcement showed low impact properties and failure compared with others, this because the sensitivity to impact damage due to of the brittleness. For $1.9 \mathrm{wc}$ composites there is a high increase in the impact properties due to high strength of the carbon in addition to the woven arrangement of the fiber which resist the crack and failure. The presences of metallic fibers makes them play an important role as a crack stopper due to the plastic deformation in the case of 1.9sf composites.

Maximum force value can be found in (1.9wf) with $3580.597 \mathrm{~N}$, followed by cf, nc, sf, and epoxy.

Maximum deformation value can be found in 1.9 sf with $22.84 \% \mathrm{~mm}$, followed by nc, cf, epoxy, and wc give the minimum value of deformation of $18 \%$.

Maximum energy value can be found in $1.9 \mathrm{wc}$ with $18.4 \mathrm{~J}$, followed by $\mathrm{cf}$, sf, nc, and epoxy give the minimum value of deformation of $2.927 \mathrm{~J}$. 


\section{REFERENCE}

[1] A. Keršys, N. Keršiene, A. Žiliukas, "Experimental Research of the Impact Response of E-Glass Epoxy and Carbon / Epoxy Composite Systems", materials science (medžiagotyra), ISSN 13921320, Vol. 16, No. 4, 2010.

[2] F.C. Campbell, "Structural Composite Materials", ASM International. www.asminternational.org, 2010.

[3] B. M. Fadhil, P. S. Ahmed, A. A. Kamal, "Improving Mechanical Properties Of Epoxy By Adding Multi-Wall Carbon Nanotube", Journal of Theoretical and Applied Mechanics, Vol. 54, No. 2, 2016, Pp. 551-560, 2016.

[4] P. S. Ahmed, B. M. Fadhil, A. A. Kamal, "Effect of Unidirectional and Woven Fibers on Impact Properties of Epoxy", Research Journal of Applied Sciences, Engineering and Technology, Vol. 12, Issue 2, Pp. 197-205, 2016.

[5] G. Agarwal, A. Patnaik, R. K. Sharma, "Mechanical And Thermo-Mechanical Properties Of Bi-Directional And Short Carbon Fiber Reinforced Epoxy Composites", Journal of Engineering Science and Technology, Vol. 9, No. 5, $590-604,2014$.

[6] H. Rahmani, S. H. M. Najafi and A. Ashori, "Mechanical Performance Of Epoxy/Carbon Fiber Laminated Composites", Journal of Reinforced Plastics and Composites, Vol. 33, No.8, pp.733740, 2014.

[7] R. H.. Mohammed, "Study the Effect of Glass Fibers on Mechanical Properties of Epoxy Composites", Eng. \& Tech. Journal .Vol.31, Part (B), No. 5, 2013.

[8] L. S. Babu and H. K. Shivan, "Impact Analysis of Laminated Composite on Glass Fiber and Carbon Fiber", International Journal of Emerging Technology and Advanced Engineering Website: www.ijetae.com, ISSN 2250-2459, ISO 9001:2008 Certified Journal, Vol. 4, Issue 6, June 2014.

[9] P. S. Ahmed, "Effect of Impactor Design on Unidirectional and Woven Fiber Reinforced Composites", Sulaimani Journal for Engineering Sciences, Vol. 3, No. 3, Pp. 21-29, 2016.

[10] N.L. Hancox, "An overview of the impact behavior of fibre-reinforced composites in Impact behavior of fiber-reinforced composite materials and structures", edited by Reid S.R. and Zhou G., CRC Press, Woodhead Pub. Ltd, 2000.

[11] B. Vieille, V. M. Casado, C. Bouvet, "Comparative Study On The Impact Behavior And Damage Tolerance Of Woven Carbon Fiber Reinforced Thermoplastic- And Thermosetting-Composites", European Conference On Composite Materials, Venice, Italy pp. 24-28, June 2012. 